\title{
CORRECTION
}

\section{Correction to: Report on the hot topic debate at ESMRMB 2021}

\author{
Najat Salameh ${ }^{1}$. David G. Norris ${ }^{2}$ (D) Andrew Webb ${ }^{3}$
}

Published online: 24 November 2021

(c) European Society for Magnetic Resonance in Medicine and Biology (ESMRMB) 2021

\section{Correction to: \\ Magnetic Resonance Materials in Physics, Biology and Medicine (2021) 34:775-778 \\ https://doi.org/10.1007/s10334-021-00972-7}

The original version of this article unfortunately contained a mistake. First author name Najat Salameh was incorrectly written as Najat Salemeh.

Publisher's Note Springer Nature remains neutral with regard to jurisdictional claims in published maps and institutional affiliations.

The original article can be found online at https://doi.org/10.1007/ s10334-021-00972-7.

David G. Norris

david.norris@donders.ru.n

1 Center for Adaptable MRI Technology, Department of Biomedical Engineering, University of Basel, Basel, Switzerland

2 Radboud University, Donders Institute for Brain, Cognition, and Behaviour, Nijmegen, The Netherlands

3 Department of Radiology, Leiden University Medical Center, Leiden, Netherlands 